\title{
PEMBERDAYAAN MASYARAKAT MELALUI PENINGKATAN NILAI PRODUK BANDREK JAHE DI KELURAHAN SIJINJANG KOTA JAMBI
}

\author{
Deny Sutrisno ${ }^{1)^{*}}$, Desi Sagita ${ }^{1)}$, Siti Hamidatul 'Aliyah ${ }^{1)}$, Yuliawati ${ }^{1)}$, Lili Andriani ${ }^{1)}$, Lia \\ Anggresani $^{1)}$, Barmi Hartesi ${ }^{1)}$, Santi Perawati ${ }^{1)}$, Rozalti ${ }^{2)}$, Hesty Murtiah ${ }^{2)}$, Susanti ${ }^{2)}$ \\ ${ }^{1)}$ Dosen prodi Farmasi STIKES Harapan Ibu Jambi \\ ${ }^{2)}$ Mahasiswa prodi Farmasi STIKES Harapan Ibu Jambi \\ *email: denysutrisno@gmail.com
}

\begin{abstract}
ABSTRAK
Masyarakat di kelurahan Sejinjang menanam Jahe merah. Jahe merah ini diolah menjadi minuman tradisional berupa bandrek jahe dalam bentuk serbuk. Olahan ini telah dijual oleh masyarakat dalam kemasan tradisional dan dengan nilai yang tidak tinggi. Tujuan pengabdian masyarakat ini adalah untuk memberdayakan masyarakat memalui peningkatan nilai produk Bandrek Jahe. Pelaksana pengabdian kepada masyarakat memberikan bantuan Kelompok binaan P2WKSS (Peningkatan Peranan Wanita Menuju Keluarga Sehat Sejahtera) untuk melakukan pengurusan izin P-IRT ke Puskesmas Tanjung Pinang dan Dinas Perindustrian dan Perdagangan Kota Jambi. Kegiatan pengabdian masyarakat sudah berhasil meningkatkan nilai produk bandrek jahe yang dibuat oleh masyarakat Kelurahan Sejinjang.
\end{abstract}

Kata Kunci: Minuman Traditional, Jahe Merah, no izin P-IRT.

\section{COMMUNITY EMPOWERMENT THROUGH UPGRADING PRODUCT VALUE OF BANDREK JAHE IN SIJINJANG OF JAMBI CITY}

\section{ABSTRACT}

People in Sijinjang of Jambi City planted red ginger. This red ginger was transform to be traditional drinking named Bandrek Jahe in powder form. This powder had been marketed by this people community through traditonal packaging with lower value. This community service program aimed to empower community through upgrading producy value of Bandrek Jahe. The activist of community service progra helped the target group named P2WKSS (Women Empowerment to Healthy and Wealthy Family) to proceed the permission number of P-IRT to Public Health Tanjung Pinang and Departement of Industry and Trade Jambi City. This community service program was succes to empower community through upgrading producy value of Bandrek Jahe made by community in Sijinjang of Jambi City.

Keywords: Traditional drinking, Red ginger, Permission number of P-IRT.

\section{PENDAHULUAN}

Kelurahan Sejinjang Kecamatan Jambi Timur Kota Jambi memiliki luas wilayah $46.336 \mathrm{~km}^{2}$. Daerah ini ditempati oleh 1.077 Kepala Keluarga. Batas wilayah Sejinjang di utara adalah Kelurahan Tanjung Johor, di selatan adalah Kelurahan Selincah, di barat adalah Kelurahan Kasang dan di timur Desa Kumpeh. Jarak dari pusat pemerintah Kecamatan adalah $4 \mathrm{~km}$. Jarak dari pusat pemerintah kota adalah $10 \mathrm{~km}$. jarak dari ibukota kabupaten $15 \mathrm{~km}$. jarak dari ibukota provinsi $15 \mathrm{~km}$.

Sebagaian besar masyarakat di kelurahan Sejinjang bekerja sebagai petani padi, tetapi ada sebagian masyarakat yang menanam Jahe merah, dimana jahe merah ini diolah menjadi minuman tradisional berupa bandrek jahe merah dalam bentuk serbuk. Olahan ini telah dijual oleh masyarakat dalam kemasan tradisional dan dengan nilai yang tidak tinggi. Kemasan untuk jahe merah tidak memang 
tidak perlu dilakukan secara khusus.serbuk jahe merah sendiri dapar bertahan sampai 629 hari pada temperatur yang cocok (Indah Yuliasih, 2006). Oleh karena itu masyarakat di kelurahan Sejinjang memerlukan peningkatan nilai produknya untuk meningkatkan nilai jual bandrek jahe ini.

Jahe dapat digunakan untuk dijadikan sebagai obat tradisional yang memiliki banyak khasiat. Jahe dapat menambah sistem imun (Darningsih et al., 2008). Selain itu jahe juga dapat mengurangi rasa mual pada ibu hamil (F. Gunanegara et al., 2010). Minuman jahe juga dapat dicampur dengan bahan lain semisal madu. Campuran jahe dan madu dapat efektif untuk mengobati keparahan batuk anak penderita ISPA (Rahmadhani, Novayelinda and Woferst, 2014). Bahan pembuatan bandrek jahe yang dilakukan oleh masyarakat di kelurahan sijinjang adalah jahe merah, gula pasir, gula merah, daun pandan, kayu manis dan serai. Cara pembuatan bandrek jahe yang dilakukan oleh masyarakat di kelurahan sijinjang adalah pertama kupas dan buang kotoran yang menempel pada jahe merah. Kemudian suci bersih jahe merah pada air yang mengalir, lalu tiriskan. Kemudian parut jahe merah dengan menggunakan parutan. Kemudian peras hasil parutan jahe merah dengan menggunakan kain flanel, hingga didapatlah air perasan jahe merahnya. Kemudian iris halus gula merah, sisihkan. Kemudian masukkan kedalam panci campuran air perasan jahe merah dengan $1 \mathrm{~kg}$ gula pasir, 1 ons irisan gula merah, 2 lembar daun pandan, 1 ruas kayu manis, dan 1 batang serai. Kemudian lalu masak semua campuran bahan-bahan tersebut dengan api sedang sambil di aduk-aduk terus selama \pm 30 menit. Kemudian setelah campuran tersebut mulai mengental (setelah \pm 20 menit pengadukan) ambil/angkat kayu manis, serai dan daun pandan yang kita masukkan tadi. Kemudian setelah \pm 30 menit campuran menjadi serbuk kasar, angkat dan dingin kan dengan cara diangin-anginkan \pm 10 menit. Kemudian setelah dingin haluskan dengan cara diblender, lalu diayak menggunakan pengayak agar didapat hasil serbuk halusnya. Maka bandrek siap dikemas dan dapat dikonsumsi dengan cara diseduh menggunakan air hangat.

Berdasarkan kondisi yang terjadi tersebut, maka timbul keinginan untuk memproduksi kembali produk bandrek jahe merah dengan bantuan kelompok binaan di kelurahan Sejinjang. Kami ingin memasarkan kembali produk bandrek jahe merah, dimana produk tersebut akan dicantumkan pula komposisi, takaran, masa kadaluarsa, dan izin dari P-IRT.

Adapun tujuan dari kegiatan pengabdian masyarakat ini adalah untuk memberdayakan masyarakat melalui peningkatan nilai produk Bandrek Jahe. Kegiatan pengabdian masyarakat ini diharapkan dapat menciptakan kewirausahaan masyarakat yang dapat 
meningkatkan perekomonian setempat. sebagai mediator para pihak yang terkait dan Selain itu juga diharapkan menciptakan bersama-sama menyelesaikan masalah yang masyarakat yang dapat berpartisipasi aktif ada dalam masyarakat. Pihak masyarakat untuk meningkatkan kemandirian dan kelurahan Sijinjang adalah Kelompok binaan kesejahteraan.

\section{METODE PELAKSANAAN KEGIATAN}

Program pengabdian masyarakat ini dilaksanakan pada bulan Septepmber 2016. Lokasi kegiatan pengabdian masyarakat ini dilaksanakan di Kelurahan Sejinjang Kecamatan Jambi Timur Kota Jambi. Peserta kegiatan ini adalah mahasiswa KKN prodi Farmasi STIKES Harapan Ibu Jambi dan masyarakat di Kelurahan Sejinjang.

Alat yang digunakan masysarakat untuk membuat bandrek jahe adalah pisau, parutan, blender, kain flanel, ayakan, panci, kompor. Adapun bahan pembuatan bandrek jahe yang dilakukan oleh masyarakat di kelurahan sijinjang adalah jahe merah, gula pasir, gula merah, daun pandan, kayu manis dan serai.

Metode pelaksanaan kegiatan pengabdian kepada masyarakat ini adalah metode pelatihan dan metode mediasi. Metode pelatihan yang dilakukan pelaksana kegiatan pengabdian kepada masyarakat ini adalah melalui penyuluhan untuk menyadarkan masyarakat untuk mengaktifkan kembali mengaktifkan kelompok binaan P2WKSS (Peningkatan Peranan Wanita Menuju Keluarga Sehat Sejahtera) di Kelurahan Sejinjang.

Pada kegiatan pelaksana pengabdian kepada masyarakat juga memposisikan diri
P2WKSS (Peningkatan Peranan Wanita Menuju Keluarga Sehat Sejahtera). Kemudian pelaksana pengabdian masyarakat melakukan mediasi pengurusan izin ke Puskesmas Tanjung Pinang dan Dinas Perindustrian dan Perdagangan Kota Jambi.

Kelompok binaan P2WKSS (Peningkatan Peranan Wanita Menuju Keluarga Sehat Sejahtera) mengelolah produk industri rumah tangga berupa Bandrek Jahe merah dan mengurus izin PIRT untuk produk bandrek jahe ini. Dalam Pengurusan izin ini, kelompok binaan membuat pengajuan bandrek jahe. Pengajuan ini diberikan kepada Puskesmas yaitu Puskesmas Tanjung Pinang agar Pihak puskesmas meneruskan pengajuannya ke Dinas Perindustrian dan Perdagangan Kota Jambi. Setelah pengajuan masuk, maka Pihak Puskesmas dan Disperindag berkunjung dan melakukan pemeriksaan ke tempat pembuatan bandrek jahe tersebut. Disperindag melihat dan memberi nilai tentang bagaimana proses kerja dan pembuatan bandrek jahenya, kesterilan pembuatannya, bagaimana lingkungan di sekitarnya, alat dan bahan apa saja yang digunakan. Setelah dilakukan pemeriksaan maka pihak Disperindag mengeluarkan izin dan sertifikat untuk bandrek jahe. Bandrek jahe siap untuk dijual kemasyarakat. 
Adapun rencana berkelanjutan dari kegiatan ini adalah tetap mengaktifkan kelompok binaan dan mengajak masyarakat di kelurahan sejinjang yang bergerak dalam bidang produksi dan pemasaran produk olahan bandrek jahe merah.

\section{HASIL DAN PEMBAHASAN}

\section{Penyuluhan dan Diskusi}

Penyuluhan dilakukan di rumah warga di kelurahan sejinjang dengan melibatkan aparat Puskesmas Tanjung Pinang masyarakat setempat (gambar 1). Penyuluhan ditujukan kepada warga dari golongan ibuibu setempat. Penyuluhan dapat meningkatkan kesejahteraan ibu dan anak (Yulianti, 2012). Adapun hal yang dibicarakan adalah mengenai pengaktifan kembali Kelompok binaan P2WKSS (Peningkatan Peranan Wanita Menuju Keluarga Sehat Sejahtera) dalam mengelolah produk industri rumah tangga berupa Bandrek Jahe merah.

Hasilnya diperoleh kesepakatan untuk pengaktifan kembali Kelompok binaan P2WKSS (Peningkatan Peranan Wanita Menuju Keluarga Sehat Sejahtera) untuk melakukan produksi dan pemasaran produk olahan bandrek jahe merah.

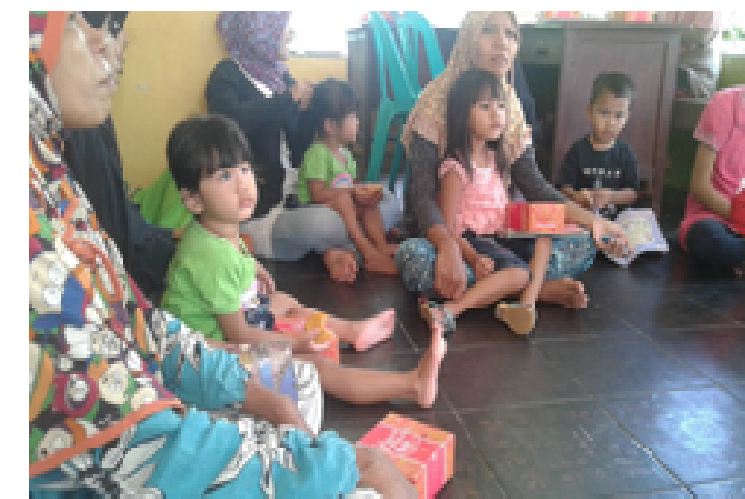

Gambar 1. Penyuluhan pengaktifan kembali kelompok binaan P2WKSS

\section{Pembuatan Jahe Merah}

Pembuatan Jahe merah dilakukan di rumah warga. Kegiatan ini dilakukan oleh ibu-ibu Kelompok binaan P2WKSS (Peningkatan Peranan Wanita Menuju Keluarga Sehat Sejahtera) yang dibantu oleh mahasiswa Prodi Farmasi STIKES Harapan Ibu Jambi. (gambar 2). Pembuatan jahe dikerjakan bersama-sama agar selesai tepat waktu karena waktu pembuatan sangat mempengaruhi hasil bubuk jahe (Ibrahim, Yunianta and Sriherfyna, 2014).



Gambar 2. Pembuatan Bandrek Jahe

Proses pembuatan bandrek jahe ini dilakukan dimulai dari bahan bentah hingga menjadi serbuk bandrek jahe (Gambar 3). Produk bandrek yang telah jadi adalah produk siap kemas dan bisa dikonsumsi dengan cara 
diseduh menggunakan air hangat.

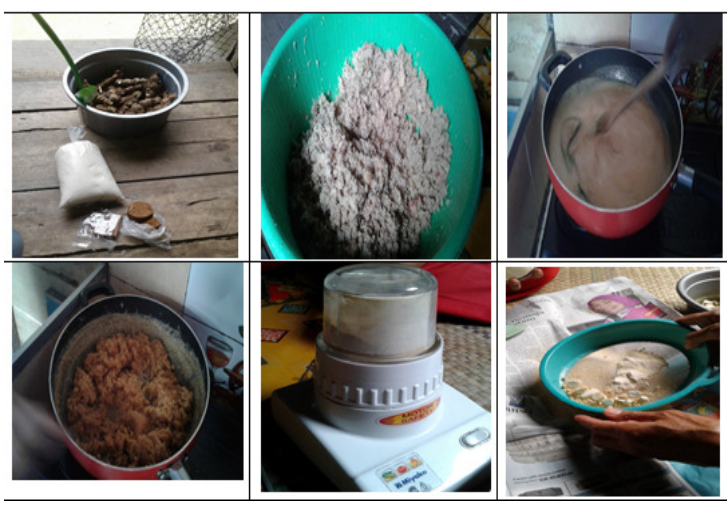

Gambar 3. Proses Pembuatan Bandrek Jahe

Pengurusan Izin P-IRT.

Kelompok binaan

P2WKSS

(Peningkatan Peranan Wanita Menuju

Keluarga Sehat Sejahtera) didampingi oleh pelaksanan pengabdian masyarakat membuat pengajuan izin bandrek jahe kepada Puskesmas Tanjung Pinang agar Pihak puskesmas meneruskan pengajuannya ke Dinas Perindustrian dan Perdagangan Kota Jambi. Kemudian Puskesmas dan Disperindag berkunjung dan melakukan pemeriksaan ke tempat pembuatan bandrek jahe di Kelurahan Sijinjang.

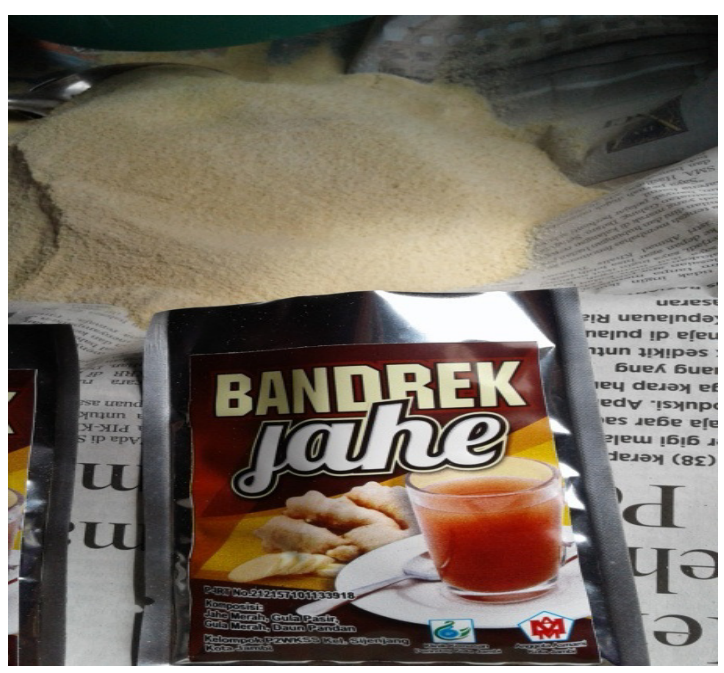

Gambar 3. Kemasan bandrek jahe yang baru yang telah mencantumkan P-IRT
Disperindag menilai nilai tentang proses pembuatan, kesterilan, lingkungan di sekitarnya, alat dan bahan. Setelah dilakukan pemeriksaan kemudian Disperindag Kota Jambi mengeluarkan izin dan sertifikat untuk bandrek jahe. Produk ini memperoleh P-IRT no 212157101133918. Sekarang bandrek jahe siap untuk dijual kemasyarakat dengan kemasan yang lebih menjual (Gambar 3).

\section{KESIMPULAN}

Kegiatan pengabdian masyarakat sudah berhasil meningkatkan nilai produk bandrek jahe yang dibuat oleh masyarakat Kelurahan Sejinjang. Partisipasi masyarakat terutama Kelompok binaan P2WKSS (Peningkatan Peranan Wanita Menuju Keluarga Sehat Sejahtera) sangat menentukan keberhasilan pencapaian ini.

\section{SARAN}

Tim pengabdian kepada masyarakat diharapkan mampu menjalin mitra dengan lembaga kepemerintahan dan masyarakat terutama kelompok binaan bidang kewirausahaan agar dapat membantu mempromosikan dan menjual hasil produk dari kelompok binaan.

\section{UCAPAN TERIMAKASIH}

Penulis mengucapkan terima kasih kepada STIKES Harapan Ibu Jambi yang telah mendukung kegiatan ini. Penulis juga mengucapkan terima kasih kepada pimpinan dan masyarakat Kelurahan Sijinjang Kecamatan Jambi Timur Kota Jambi terutama Kelompok binaan P2WKSS (Peningkatan 
Peranan Wanita Menuju Keluarga Sehat

Sejahtera).

\section{REFERENSI}

[1] Darningsih, S. et al. (2008) 'Formulasi Teh Camelia-Murbei Dengan Bubuk Jahe (Zingiber Officinale) Dan Asam Jawa (Tamarindus Indica, L.) Sebagai Minuman Kesehatan Untuk Meningkatkan Respon Imun Tikus', Jurnal Gizi dan Pangan, 3(2), p. 61. doi: 10.25182/jgp.2008.3.2.61-70.

[2] F. Gunanegara, R. et al. (2010) UNISWA Research Journal of Agriculture Science and Technology, Jurnal Kedokteran Maranatha. Available at: http://majour.maranatha.edu/index.php/j urnal-kedokteran/article/view/146 (Accessed: 5 April 2018).

[3] Ibrahim, A. M., Yunianta, Y. and Sriherfyna, F. H. (2014) 'Pengaruh Suhu Dan Lama Waktu Ekstraksi Terhadap Sifat Kimia Dan Fisik Pada Pembuatan Minuman Sari Jahe Merah (Zingiber Officinale Var. Rubrum) Dengan Kombinasi Penambahan Madu Sebagai Pemanis', Jurnal Pangan dan Agroindustri, 3(2). Available at: http://jpa.ub.ac.id/index.php/jpa/article/v iew/171 (Accessed: 5 April 2018).

[4] Indah Yuliasih, S. dan T. (2006) Pendugaan Umur Simpan Bubuk Jahe Merah (Zingiber Officinale Var. Rubrum), Journal of Agroindustrial Technology. Available at: http://journal.ipb.ac.id/index.php/jurnalti n/article/view/4255 (Accessed: 5 April 2018).

[5] Rahmadhani, A. N., Novayelinda, R.and Woferst, R.- (2014) 'Efektifitas pemberian minuman jahe madu Terhadap keparahan batuk pada anak dengan ispa', Jurnal Online Mahasiswa (JOM) Bidang Ilmu Keperawatan, 1(2), pp. 1-7. Available at: http://jom.unri.ac.id/index.php/JOMPSI K/article/view/4137 (Accessed: 5 April 2018).

[6] Yulianti (2012) 'Efektifitas Penyuluhan Terhadap Peningkatan Kesejahteraan Anak Pada Ibu-Ibu Kelompok Keluarga
Sejahtera 1', Jurnal Didaktika Dwija Indria (SOLO), 2(1). Available at: http://jurnal.fkip.uns.ac.id/index.php/pgs dsolo/article/view/121 (Accessed: 5 April 2018). 